\title{
Hydatid disease with Aspergilloma: A unique case report
}

\author{
Sandeep Sharma, Parikshit Thakare, Ketaki Utpat, Unnati Desai \\ Department of Pulmonary Medicine, Topiwala National Medical College and BYL Nair Hospital, Mumbai, India
}

\begin{abstract}
The coexisting presence of hydatid disease with aspergillus colonization is a rare finding. The 20 -year-old presented with symptoms of hemoptysis with past history of tuberculosis. On further evaluation patient was diagnosed as a case of aspergilloma and managed conservatively. After one year on presenting with similar complaints patient was turned out to be hydatid disease with aspergillus colonization on the basis of clinic-radiological and bronchoscopic evaluation. Till now only few case reports have been reported. We report a unique case report of similar presentation.
\end{abstract}

Correspondence: Unnati Desai, Department of Pulmonary Medicine, Topiwala National Medical College and BYL Nair Hospital, Mumbai 400008, India.

Tel.+91.022.23027642/43.

E-mail: unnati_desai82@yahoo.co.in

Contributions: All the authors made a substantive intellectual contribution. All the authors have read and approved the final version of the manuscript and agreed to be accountable for all aspects of the work.

Conflict of interest: The authors declare that they have no competing interests, and all authors confirm accuracy.

Availability of data and materials: All data underlying the findings are fully available.

Ethics approval and consent to participate: No ethical committee approval was required for this case report by the Department, because this article does not contain any studies with human participants or animals.

Consent for publication: The patient gave his written consent to use his personal data for the publication of this case report and any accompanying images.

Key words: Hydatid disease; hemoptysis; aspergillus colonization.

Received for publication: 5 August 2020.

Accepted for publication: 15 November 2020.

${ }^{\circ}$ Copyright: the Author(s), 2021

Licensee PAGEPress, Italy

Monaldi Archives for Chest Disease 2021; $91: 1549$

doi: 10.4081/monaldi.2021.1549

This article is distributed under the terms of the Creative Commons Attribution Noncommercial License (by-nc 4.0) which permits any noncommercial use, distribution, and reproduction in any medium, provided the original author(s) and source are credited.

\section{Introduction}

Aspergillosis is a fungal infection caused due to interaction between the offending pathogen and host immune system or hypersensitivity reaction. The aspergillosis can develop in cavities formed as a result of tuberculosis, sarcoidosis, bronchiectasis and lung abscess. The hydatid disease is a parasitic infection caused by Echinococcus granulosus. Symptoms of both hydatid disease and aspergillus infection are indistinguishable. Imaging modalities Chest X Ray, HRCT thorax and serological test for Echinococcus granulosus helps to distinguish between aspergillus infection and hydatid disease. The co-existence is very rare and only few case reports have been reported till now. We report a case report of similar presentation.

\section{Case Report}

A 20-year-old male, non-addict, immunocompetent presented in out-patient department with chief complaints of episodic cough with mucoid expectoration which was associated with streaky hemoptysis with episodic breathlessness for 2 years, with past history of empirical anti tuberculosis therapy intake for 6 months one and half year ago. On clinical examination his vitals were stable. The chest examination was within normal limits with bilateral equal breath sounds.

The previous investigations of the patient were suggestive of patient having right upper zone opacity with air crescent suggestive of aspergilloma which has been managed with cough suppressant and tranexamic acid along with tablet Itraconazole (200mg) twice a day for one month duration.

Later on, patient had 12 months of asymptomatic period following treatment. Subsequently patient again developed cough with streaky hemoptysis and evaluated with sputum for acid-fast bacilli AFB under fluorescent microscopy, which was negative, elevated serum Ig E levels- $1398 \mathrm{IU} / \mathrm{ml}$ and negative serum antibody IgG against Echinococcus granulosus - $3.41 \mathrm{IU} / \mathrm{ml}$. The radiological imaging like chest X-ray (Figure 1) was showing right upper zone cavity with air crescent sign and dual energy computed tomography DECT Thorax (Figures 2 and Fgure 3) with comparative assessment of previous CT scans was suggestive of complex lesion of $3.8 \times 2.9 \mathrm{~cm}$ in size in right upper lobe with eccentric air crescent; which was unchanged from last study with better appreciation of the lamellated appearance with multiple air foci likely to be a hydatid cyst or a complex fungal ball.

Then patient underwent bronchoscopy and bronchial washing were taken for parasitology, fungal smear and fungal culture which were negative. The patient was planned for CT guided biopsy of right upper lobe lesion for diagnostic evaluation and biopsy sample was sent for Acid fast Bacilli (AFB) smear and AFB cul- 
ture and fungal culture. The histopathology report (Figure 4) was suggestive of tiny fragments of laminated, hyaline, acellular cyst wall showing colonization by septate, narrow angle, branching fungal filaments, highlighted by Gomori Methamine Silver stain (GMS stain) consistent with diagnosis of hydatid cyst with aspergillus colonization. The final diagnosis of the patient was right upper lobe soft tissue lesion due to hydatid cyst with aspergillus colonization.

The patient was started on tablet albendazole $10 \mathrm{mg} / \mathrm{kg} /$ day with liver function test monitoring for total duration of 12 months and first follow up visit after one month showed clinic-radiological improvement.

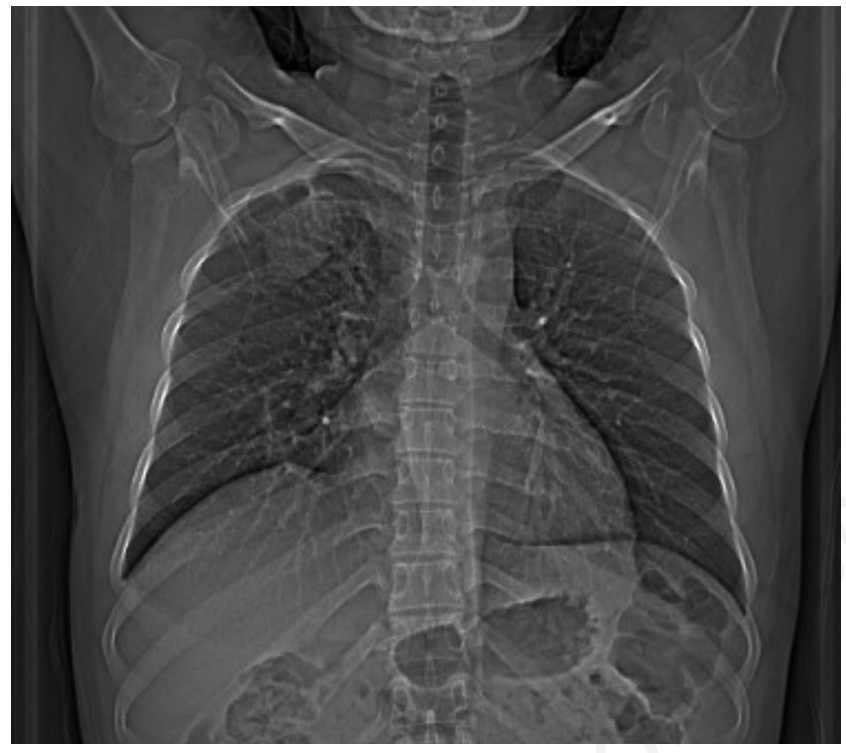

Figure 1. Chest X-ray showing right upper zone cavity with air crescent sign.

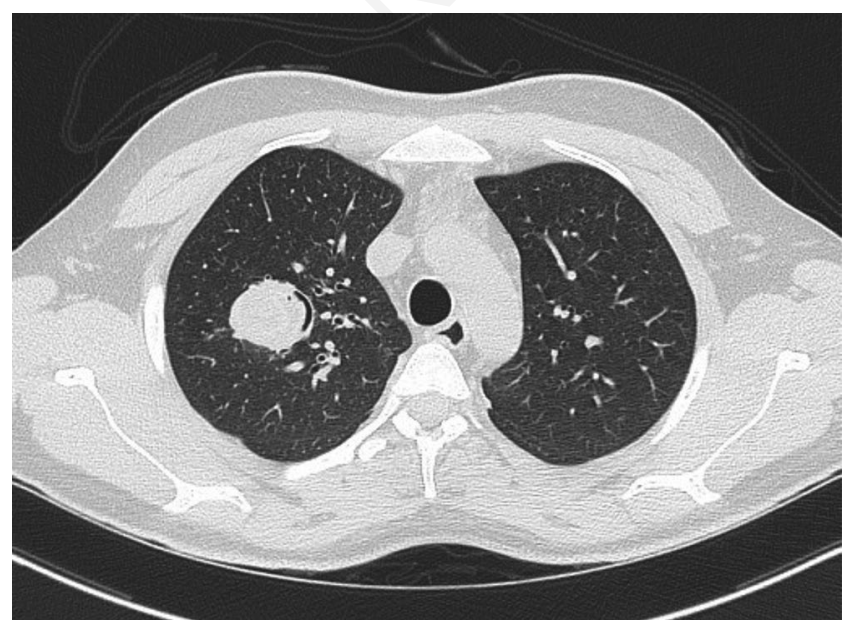

Figure 2. CT thorax image showing right upper lobe opacity with eccentric air crescent (transverse axis-supine position).

\section{Discussion}

Aspergillus is the most common pathogen causing pulmonary fungal disease worldwide. Aspergillus infection-related pulmonary disease can have different presentations like allergic bronchopulmonary aspergillosis, acute invasive pulmonary aspergillosis (IPA) and chronic pulmonary aspergillosis (CPA) [1-3].

Chronic pulmonary aspergillosis is a complex syndrome which ranges from simple aspergilloma to other progressive cavitatory diseases like chronic cavitary pulmonary aspergillosis (CCPA), chronic necrotising pulmonary aspergillosis (CNPA), and chronic fibrosing pulmonary aspergillosis (CFPA). Patients with CPA are generally non-immune compromised with underlying lung conditions as cavities, chronic obstructive pulmonary disease, bullous lung disease, past history of pulmonary tuberculosis, bronchiecta-

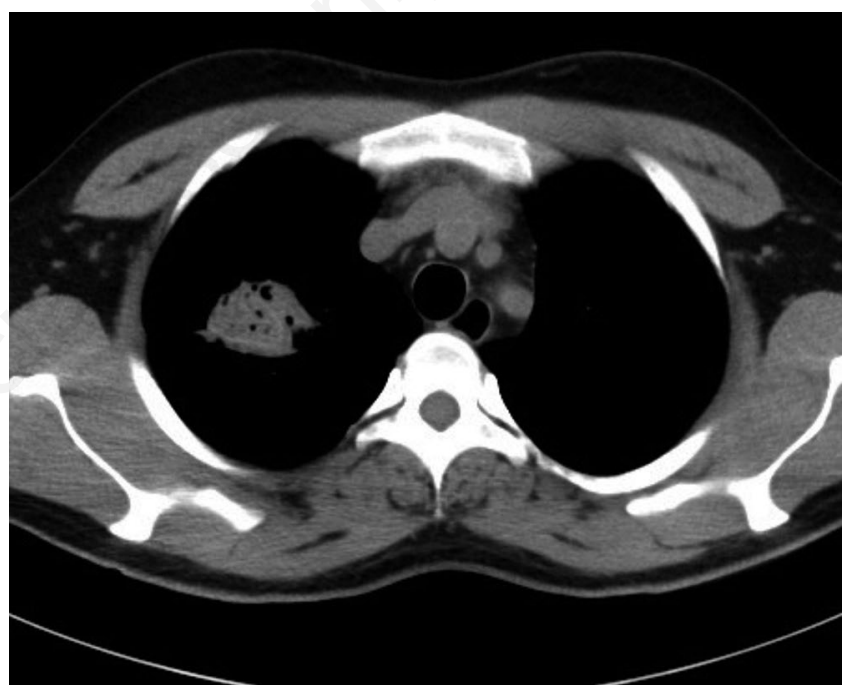

Figure 3. DECT thorax image showing right upper lobe opacity with eccentric air crescent and lamellated appearance and multiple air foci (transverse axis).

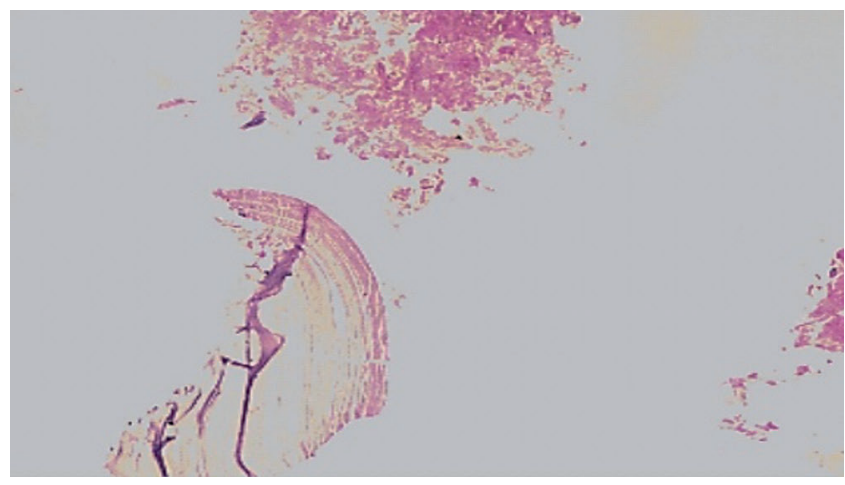

Figure 4. CT guided biopsy. Histopathology image showing hydatid cyst with aspergillus colonization (H\&E stain; 10x magnification). 
Table 1. Cases of Aspergilloma colonization reported in literature.

\begin{tabular}{|c|c|c|c|}
\hline Age & Clinical presentation & Radiological presentation & Diagnosis \\
\hline 45-year Male & $\begin{array}{l}\text { Breathlessness } \\
\text { Recurrent hemoptysis } \\
\text { Non resolving pneumonia } \\
\text { Intermittent fever }\end{array}$ & $\begin{array}{l}\text { Well defined, peripherally enhancing, } \\
\text { thick-walled cystic lesion in middle lobe } \\
\text { of right lung }\end{array}$ & $\begin{array}{l}\text { Dual infection of Echinococcus and Aspergillus [13] } \\
\text { diagnosed on histopathology of VATS (Video Assisted } \\
\text { Thoracic Surgery) middle lobectomy }\end{array}$ \\
\hline 32-year Male & $\begin{array}{l}\text { Chest pain } \\
\text { Productive cough }\end{array}$ & $\begin{array}{l}\text { Cystic lesion with air fluid level in left lung } \\
\text { Hypodense cystic lesion in segment } V \text { and VII } \\
\text { of right lobe of liver }\end{array}$ & $\begin{array}{l}\text { Hydatid cyst invaded by aspergillus invasion [14] } \\
\text { diagnosed on histopathology done by decorticationl }\end{array}$ \\
\hline 27-year Male & $\begin{array}{l}\text { Fever } \\
\text { Productive cough }\end{array}$ & $\begin{array}{l}\text { Lingular lobe thick-walled cavity with irregular } \\
\text { fluid level }\end{array}$ & $\begin{array}{l}\text { Hydatid cyst with Aspergillus invasion [15] diagnosed } \\
\text { on histopathology by surgical resection }\end{array}$ \\
\hline 24 year Male & $\begin{array}{l}\text { Epigastric pain } \\
\text { Vomiting } \\
\text { Fever }\end{array}$ & $\begin{array}{l}\text { Well-defined cavitatory lesion with wall } \\
\text { calcification and air fluid level in lingular } \\
\text { segment of left lung }\end{array}$ & $\begin{array}{l}\text { Hydatoptysis [16] on sputum cytology showing } \\
\text { multiple hooklets and scolices with thin slender } \\
\text { hyphal elements of aspergillus on potassium mount } \\
\text { examination }\end{array}$ \\
\hline
\end{tabular}

sis, pneumothorax. The most common presenting symptoms being cough, hemoptysis, dyspnea, fever. The simple aspergilloma is usually asymptomatic or can present with mild symptoms like streaky hemoptysis. The progressive cavitatory diseases have high morbidity due to complications like massive hemoptysis.

Imaging findings in patients with CPA consist mainly of cavities, fungus balls, pleural thickening and pericavitary consolidation in the upper lobes $[4,5]$. The treatment of pulmonary aspergillosis diseases is usually conservative management and pharmacotherapy in the form of azole antifungal agents. Surgical resection is considered in cases of aspergilloma for massive hemoptysis.

Human echinococcosis (Hydatid disease) is a parasitic disease which is most commonly caused by Echinococcus granulosus. The hydatid disease is commonly seen in slaughterers, tanners, stockbreeders, shepherds, butchers, and veterinarians or any job which makes a person to work closely with animals [6].

The clinical features of hydatid cysts depend on the site and size of the cyst and the presence of complications. Uncomplicated small, peripherally located cysts often remain asymptomatic and are discovered incidentally on chest radiography. Clinical symptoms occur when the cysts grow large enough to exert mechanical effects on the adjacent structures or to develop complications [7]. Complications of pulmonary hydatid cysts include rupture, secondary infection, pneumothorax, and suppuration, calcification. Another important feature of rupture is the development of hypersensitivity reactions ranging from urticaria and wheezing to anaphylaxis. The classical chest radiography of an intact cyst is a sharply defined, round-to-oval homogenous opacity of variable size. Serological testing like enzyme-linked immunosorbent assay (ELISA) is useful in the primary diagnosis of hydatid cysts

Pulmonary hydatid cysts are treated by pharmacotherapy and/or surgery. Medical therapy of pulmonary hydatid cyst includes benzimidazoles group of drugs like mebendazole (MBZ) or albendazole (ABZ). The indications for surgery include large cysts that are superficial and likely to rupture, infected cysts, cysts in vital anatomical locations, and cysts exerting substantial mass effect. The available surgical option includes enucleation, pericystectomy, cystostomy with capitonnage, open aspiration, and lung resection.

Aspergillosis and echinococcosis share the same symptoms and crescent signs on chest $\mathrm{CT}[8,9]$, making difficult to distinguish. From 100 archival cases of hydatid disease, Koçer et al. found two cases of simultaneous Aspergillus infection, and only in the lung [10]. Gupta et al. [11] proposed that fungi could invade the wall of the ectocyst and breed in the pericyst cavity. It was also suggested that a pressure difference would allow fungal to live in the pericyst cavity [12]. There are some cases similar to our case reported in literature with different clinical and radiological presentation mentioned in Table 1.

Thus, it is important to keep in mind differential diagnosis of hydatid disease with cystic and cavitatory lesion of lung with clinic-radiological co-relation. Early diagnosis and management of hydatid disease with aspergillus colonization helps preventing life threatening complications like hemoptysis.

\section{References}

1. Kousha M, Tadi R, Soubani AO.Pulmonary aspergillosis: a clinical review. Eur Respir Rev 2011;20:156-74.

2. Limper AH, Knoz KS, Sarosi GA et al. An official American Thoracic Society statement: treatment of fungal infection in adult pulmonary and critical care patients. Am J Respir Crit Care Med 2011;183:96-128.

3. Godet C, Philippe B, Laurent F, Cadranel J. Chronic pulmonary aspergillosis: an update on diagnosis and treatment. Respiration 2014;88:162-74.

4. Ando T, Tochigi N, Gocho K, et al. Pathological implication of computed tomography images of chronic pulmonary aspergillosis. Jpn J Infect Dis 2016;69:118-26.

5. Godet C, Laurent F, Bergeron A, et al. CT imaging assessment of response to treatment in chronic pulmonary aspergillosis. Chest 2016;50:139-47.

6. Farahmand M, Yadollahi M. Echinococcosis: An occupational disease. Int J Occup Environ Med 2010;1:88-91.

7. Shehatha J, Alizzi A, Alward M, Konstantinov I. Thoracic hydatid disease; a review of 763 cases. Heart Lung Circ 2008;17:502-4.

8. Morar R, Feldman C. Pulmonary echinococcosis. Eur Respir J 2003;21:1069-77.

9. Soubani AO, Chandrasekar PH. The clinical spectrum of pulmonary aspergillosis. Chest 2002;121:1988-99.

10. Koçer NE, Kibar Y, Güldür ME, et al. A retrospective study on the coexistence of hydatid cyst and aspergillosis. Int J Infect Dis 2008; $12: 248-51$. 
11. Gupta N, Arora J, Nijhawan R, et al. Aspergillosis with pulmonary echinococcosis. Cytojournal 2006;3:7.

12. Date A, Zachariah N. Saprophytic mycosis with pulmonary echinococcosis. J Trop Med Hyg 1995;98:416-8.

13. Goyal RC, Tyagi R, Garg B, et al. Pulmonary hydatid disease with Aspergillosis-An unusual association in an immunocompetent host. Turk Patoloj Derg 2018;35:166-9.

14. Chatterjee A, Goswami HM, Dhotre SV, et al. A retrospective study on coexistence of pulmonary hydatid cyst and aspergillosis. Int J Microbiol Res 2012;4:279.

15. Mahmood N, Azam H, Ali MI, Khan MA. Pulmonary hydatid cyst with complicating Aspergillus infection presenting as a refractory lung abscess. Clin Med Insights Case Rep 2011;4:63-8.

16. Raja VA, Sindhu G, Sreevidya B, et al. A rare case of hydatoptysis. Indian J Chest Dis Allied Sci 2018;60:83-5. 